\title{
Complete allelic analysis of BRCA 1 and BRCA2 variants in young Nigerian breast cancer patients
}

\author{
J D Fackenthal, L Sveen, Q Gao, E K Kohlmeir, C Adebamowo, T O Ogundiran, A A Adenipekun, \\ R Oyesegun, O Campbell, C Rotimi, E E U Akang, S Das, O I Olopade
}

J Med Genet 2005;42:276-281. doi: 10.1136/jimg.2004.020446

B reast cancer is a leading cause of cancer deaths among women, and is expected to claim the lives of nearly 40000 individuals in the USA each year (American Cancer Society Breast Cancer Facts and Figures 2003-2004). Only $5-10 \%$ of breast cancers are associated with mutations in the susceptibility genes BRCAI and BRCA2. However, in cases associated with strong family history, mutation rates are higher, ranging from $16 \%$ to $26 \%$ for $B R C A l^{1-3}$ and from $7 \%$ to $13 \%$ for BRCA2. ${ }^{23}$ However, many breast cancer patients with strong family histories have no obvious mutations in $B R C A I / 2$. While there is an active search for other breast cancer susceptibility genes, it is possible that the true contributions of BRCAI and BRCA2 to early onset breast cancer have been underestimated. Indeed, one study has shown that only $63 \%$ of breast cancer families linked to $B R C A I$ are associated with detectable mutations in BRCAl. ${ }^{4}$ Several reasons for this discrepancy are possible. For example, mutations in BRCAl promoter sequences might be undetectable by current detection techniques. Additionally, inherited genomic rearrangements that inactivate BRCAl and $B R C A 2$ but cannot be detected by conventional polymerase chain reaction (PCR) based assays have been reported..$^{5-10}$ Finally, it is possible that some genetic variants previously dismissed as "unclassified variants" or "polymorphisms" may have hitherto underappreciated effects on protein synthesis or function.

Most studies of BRCAI and BRCA2 associated breast cancers have focused on white populations, yet several observations suggest that there might be a genetic component to breast cancer susceptibility in families of African ancestry. ${ }^{11}$ Breast cancer is less common in African populations than in other populations but, when it does occur, it is characterised by an early age of onset and a higher mortality. ${ }^{12-14}$ Additionally, histopathological studies have revealed striking similarities between breast tumours that occur in BRCAI mutation carriers and patients of African descent, including a higher likelihood of being high grade, hormone receptor negative, and showing increased S-phase and nuclear atypia. ${ }^{15-21}$

Thus it is important to know whether BRCAl and/or BRCA2 mutations play any role in the early onset breast cancers that disproportionately affect patients of African ancestry. We previously described the first analysis of truncating BRCAl and BRCA2 alleles in a population of Nigerian breast cancer patients aged 40 years or younger..$^{22}$ This study showed that, while protein truncating alleles are surprisingly less frequent in the Nigerian cohort than other populations studied, the total level of genetic variability in these genes was very high. In the present study, we examine whether non-truncating alleles of BRCAI or BRCA2 are associated with breast cancers in a similar cohort. Specifically, we addressed whether $B R C A I / 2$ sequence variations are more frequent in African

\section{Key points}

- Breast cancer in African women is less common than in other groups, but it strikes at an earlier age and has a higher mortality. Breast cancers that result from inherited BRCA1 and BRCA2 mutations are also associated with early age of onset and poor prognosis.

- The frequency and mutational spectra of BRCAl and BRCA2 germline mutations were analysed in 39 Nigerian breast cancer patients aged $\leqslant 40$ years unselected for family history. In this cohort, 29/39 $(74 \%)$ carried at least one BRCA $1 / 2$ genetic variation, with $69 \%$ having sequence variations in BRCA2. This represents a higher frequency of $B R C A 2$ variants than previously seen in a clinic based high risk white cohort.

- Despite this extensive amount of genetic variation, only one truncating allele was detected (BRCA2 3034del4). The remaining alleles included 24 exonic single base substitutions, of which four (E425E, L1357L, E1806E, V2171V) have been reported only in Africans or African Americans.

- While no candidate founder mutations emerged from this analysis, five of the 13 different variants detected (38\%) were rare non-protein-truncating BRCA2 alleles and undetected in a population of 74 unaffected Nigerian control subjects. As this frequency difference of rare alleles in cases and controls cannot be statistically significant, modelling software was used to predict whether these alleles represent functionally disruptive amino acid substitutions or potential splicing defects.

- 11 different BRCA1/2 alleles were shown to be potentially deleterious by one of these criteria, suggesting that the significant level of genetic variation in BRCAl and BRCA2 may contribute to breast cancer risk in populations of African ancestry.

breast cancer populations than in other populations; whether there is a distinctive spectrum of $B R C A l / 2$ sequence variations in African patients that may identify functionally critical protein domains; and whether there are founder mutations that occur frequently in breast cancer populations of African descent.

Abbreviations: ESE, exonic splicing enhancer; HA, heteroduplex analysis; PTT, protein truncation test; SNP, single nucleotide polymorphism 


\begin{tabular}{|c|c|c|c|c|}
\hline \multicolumn{2}{|c|}{ Patient } & $\begin{array}{l}\text { Age } \\
\text { (years) }\end{array}$ & BRCAI & BRCA2 \\
\hline \multicolumn{5}{|c|}{ Variants detected } \\
\hline \multirow[t]{7}{*}{1} & $98-168-1$ & 27 & & N991D \\
\hline & & & & P1088P \\
\hline & & & & T1414M \\
\hline & & & & E1806E \\
\hline & & & & D1902N \\
\hline & & & & L1904V \\
\hline & & & & $\begin{array}{l}\mathrm{H} 2440 R \\
\text { ex21-36C } \rightarrow G\end{array}$ \\
\hline 2 & $98-169-1$ & 38 & & V2171V \\
\hline 3 & $98-171-1$ & 33 & & ex18+109G $\rightarrow A$ \\
\hline 4 & $98-172-1$ & 32 & & $\begin{array}{l}\text { A248T } \\
\text { ex } 18+109 \mathrm{G} \rightarrow \mathrm{A}\end{array}$ \\
\hline 5 & $98-173-1$ & 31 & $\mathrm{~K} 1183 \mathrm{R}$ & I2944F \\
\hline 6 & $98-174-1$ & 35 & & ex $2-11 C \rightarrow T$ \\
\hline 7 & $98-176-1$ & 37 & & ex7-19C $\rightarrow T$ \\
\hline 8 & $98-181-1$ & 37 & I379M & \\
\hline 9 & $98-185-1$ & 38 & P938P & $e \times 2-11 C \rightarrow T$ \\
\hline 10 & $98-187-1$ & 40 & & ex7-19C $\rightarrow T$ \\
\hline 11 & 98-194-1 & 40 & & $\begin{array}{l}12944 \mathrm{~F} \\
\text { exl7-40A } \rightarrow \mathrm{G}\end{array}$ \\
\hline 12 & $98-198-1$ & 40 & & exl7- $40 \mathrm{~A} \rightarrow \mathrm{G}$ \\
\hline 13 & 98-203-1 & 40 & & L1904V \\
\hline 14 & $98-215-1$ & 40 & & N991D \\
\hline \multirow[t]{3}{*}{15} & $98-219-1$ & 37 & & L1521L \\
\hline & & & & V2171V \\
\hline & & & & exl7- $40 \mathrm{~A} \rightarrow \mathrm{G}$ \\
\hline 16 & 98-220-1 & 29 & & ex26+106delT \\
\hline \multirow[t]{4}{*}{17} & $98-221-1$ & 38 & & E425E \\
\hline & & & & G3212R \\
\hline & & & & Q713L \\
\hline & & & & ex26+106delT \\
\hline \multirow[t]{2}{*}{18} & $98-228-1$ & 38 & & N987I \\
\hline & & & & L929S \\
\hline 19 & $98-231-1$ & 38 & & $958 \mathrm{x}$ \\
\hline \multirow[t]{6}{*}{20} & $98-244-1$ & 35 & & E425E \\
\hline & & & & $\mathrm{G} 3212 \mathrm{R}$ \\
\hline & & & & Q713L \\
\hline & & & & $\mathrm{ex} 2-11 \mathrm{C} \rightarrow \mathrm{T}$ \\
\hline & & & & exi1-43T $\rightarrow C$ \\
\hline & & & & ex $11-43 T \rightarrow C$ \\
\hline 21 & $98-245-1$ & 33 & & ex12-200insC \\
\hline \multirow[t]{3}{*}{22} & $98-247-1$ & 33 & & P1088P \\
\hline & & & & E1806E \\
\hline & & & & H2440R \\
\hline \multirow[t]{2}{*}{23} & $98-254-1$ & 40 & & N991D \\
\hline & & & & $12944 \mathrm{~F}$ \\
\hline 24 & $98-255-1$ & 39 & K820E & \\
\hline \multirow[t]{3}{*}{25} & $98-260-1$ & 38 & & N991D \\
\hline & & & & ex2-11C $\rightarrow T$ \\
\hline & & & & $\mathrm{N} 289 \mathrm{H}$ \\
\hline 26 & $98-263-1$ & 38 & & V2171V \\
\hline 27 & $98-267-1$ & 38 & & V2171V \\
\hline \multirow[t]{3}{*}{28} & $98-270-1$ & 40 & & L1357L \\
\hline & & & & Q2384K \\
\hline & & & & $\mathrm{S} 2414 \mathrm{~S}$ \\
\hline 29 & $98-274-1$ & 30 & & ex22-70C $\rightarrow T$ \\
\hline \multicolumn{5}{|c|}{ No variants detected } \\
\hline 30 & $98-182-1$ & 34 & & \\
\hline 31 & $98-188-1$ & 37 & & \\
\hline 32 & $98-225-1$ & 35 & & \\
\hline 33 & $98-227-1$ & 30 & & \\
\hline 34 & $98-229-1$ & 30 & & \\
\hline 35 & $98-232-1$ & 31 & & \\
\hline 36 & $98-234-1$ & 35 & & \\
\hline 37 & $98-236-1$ & 33 & & \\
\hline 38 & $98-253-1$ & 40 & & \\
\hline 39 & $98-261-1$ & 39 & & \\
\hline
\end{tabular}

\section{METHODS}

Human subjects

Genomic DNA was prepared from peripheral blood from breast cancer patients using DNA isolation kits from
Puregene (Gentra Systems, Minneapolis, Minnesota, USA) according to the manufacturer's instructions. Patients were all Nigerian women diagnosed with breast cancer at the age of 40 years or younger (median age 37 years; range 27 to 40 ), and samples were selected from a consecutive series of newly diagnosed breast cancer cases seen at the University College Hospital, Ibadan, Nigeria. Thirty three of 39 patients (85\%) reported no family history of cancer. Of the remaining six $(15 \%)$, five reported one case of breast cancer in a first degree relative, and one reported cervical cancer in her sister and grandmother. The patient distribution among Nigerian ethnic groups was as follows: 25 Yoruba (64.1\%); three Igbo (7.7\%); three Urhobo (7.7\%); two Edo (5.1\%); one Delta (2.6\%); one Goemai $(2.6 \%)$; one Kagoro (2.6\%); one Ishan (2.6\%); one Owan (2.6\%); and one unknown (2.6\%). Thus most of the cases were Yorubas.

Seventy four control subjects, also Nigerian women seen at the University College Hospital at Ibadan, were given breast examinations to confirm that no breast cancer was present. These women had a median age of 37 years old (range 22 to $66)$. Seventy of them $(94.6 \%)$ reported no family history of breast cancer. The remaining four (5.4\%) reported cancers in first degree relatives but did not specify the type of cancer. The control distribution among Nigerian ethnic groups was as follows: 67 Yoruba $(90.5 \%)$ : two Igbo $(2.7 \%)$; two Edo (2.7\%); one Urhobo (1.4\%); and one Tbibio (1.4\%). Thus, as with the cases, the controls were predominantly Yorubas.

All patients and control subjects gave informed consent after appropriate counselling according to the protocols approved by the Universities of Chicago and Ibadan institutional review boards.

\section{Heteroduplex analysis}

We screened the entire coding sequence and all intron/exon junctions using heteroduplex analysis (HA) followed by DNA sequencing as previously published..$^{23}$ Briefly, PCR products were heated at $95^{\circ} \mathrm{C}$ for three minutes, then slowly cooled to $37^{\circ} \mathrm{C}$ over 40 minutes. After mixing with $6 \times$ triple dye loading buffer at 1:5 volume ratio, the PCR products were run on $1 \times$ MDE gel (FMC BioProducts, Rockland, Massachusetts, USA) with $15 \%$ urea at 400 volts at room temperature for 14 to 20 hours. The gels were stained with in SYBR ${ }^{\mathrm{TM}}$ Green I nucleic acid (FMC BioProducts) and photographed under ultraviolet light.

\section{Protein truncation test}

In addition to heteroduplex analysis, the protein truncation test (PTT) was used to screen genomic DNAs of exon 10 from $B R C A 2$ and exon 11 from both BRCAl and BRCA2, as previously published. ${ }^{24}$ The forward primers include additional $5^{\prime}$ sequences containing the T7 promoter and a translation start site. PTT using the TNT-T7 coupled wheat germ extract system (Promega, Madison, Wisconsin, USA) was carried out according to the manufacturer's instructions, incorporating ${ }^{35} \mathrm{~S}$-methionine or ${ }^{35} \mathrm{~S}$-cysteine. Samples were electrophoresed on $12.5 \%$ acrylamide gels and exposed to Kodak $x$ ray film. Candidate positives were sequenced.

\section{DNA sequencing}

PCR products showing an electrophoretic variant pattern by HA or PTT were reamplified from the original genomic DNA and both strands were directly sequenced by the fluorometric method with automated sequencing procedures (Dyedeoxy Terminator cycle sequencing kit and ABI377 DNA sequencer; Applied Biosystems, Foster City, California, USA).

\section{Analysis of variants}

Data regarding clinical significance and ethnic occurrence of previously reported alleles were taken from the breast cancer 
information core (BIC) website http://research.nhgri.nih.gov/ bic/. Predictions of exonic splicing enhancer (ESE) consensus scores were made using previously described scoring matrices. ${ }^{25-27}$ Predictions of which amino acids are not theoretically tolerated at specific positions within BRCAl and BRCA2 were generated using the "sorting intolerant from tolerant" (SIFT) website http://blocks.fhcrc.org/sift/ SIFT.html. This method searches public databases for protein homologs, performs alignments, and then generates a score for the theoretical tolerance of each possible amino acid substitution. Records used for single nucleotide polymorphism (SNP) frequencies are kept in the SNP500Cancer database http://snp500cancer.nci.nih.gov/.

\section{RESULTS}

In this cohort of early onset Nigerian breast cancer cases, 29 of $39(74 \%)$ carried at least one genetic variation in BRCAl, $B R C A 2$, or both. BRCA2 variations were found in a surprising 27 cases $(69 \%)$ (table 1$)$. Thirty four different variants were detected, four in BRCAl and 30 in BRCA2 (table 2). These included nine intronic and 25 exonic variations. Of these variations, only one $(2.5 \%)$ is a known deleterious truncating mutation (BRCA2 3034del4). Of the 21 previously reported non-truncating exonic variants, ${ }^{28} 15$ are described as "unclassified variants" and only six are described as polymorphisms. The remaining four exonic variants are reported here for the first time. Seven of the nine BRCA2 intronic variations have not been reported previously. It is important to note that the heteroduplex method used here identifies heterozygous genotypes, and the frequencies of the alleles reported does not include the frequencies of potential variant homozygotes.

To test the potential clinical significance of these variants, we examined the frequency of amino acid substitution variants in a population of 74 unaffected Nigerian samples (that is, 148 chromosomes) (table 2). BRCAI and BRCA2 single base changes not expected to result in amino acid substitutions were not examined. Five of 13 predicted BRCA2 amino acid substitution variants $(38 \%)$ were not detected in the unaffected population, indicating that they may be rare high risk alleles. However, several of the alleles found in the Nigerian cohort have been described as single nucleotide polymorphisms (SNPs) by the National Cancer Institute cancer genome anatomy project "SNP500Cancer" database (http://snp500cancer.nci.nih.gov/). It is reported that BRCA2 alleles N289H, L929S, N987I, N991D, S2414S, H2440R, and I2944F all exist in reference samples and are just as frequent in patients of African ancestry as in those of other ethnicities. Curiously, the BRCA1 K1183R allele is also described as an SNP found in unaffected populations, but may be less common in individuals of African ancestry. However, the alleles found in our patient set but not in our control population (BRCA2 A248T, Q713L, D1902N, L1904V, and Q2384K) are also not described in the SNP database. While it is possible that these rare variants found in patients may be deleterious, we did not have sufficient power to determine whether their absence from control populations was statistically significant.

To investigate whether exonic base changes found in African BRCA1 and BRCA2 variants might affect correct message splicing, we examined exonic base changes and the surrounding sequence for disruption of high scoring ESE consensus sequences. ${ }^{25-27}$ 30-32 ESEs are SR protein binding sequences that may lie within exons of pre-mRNAs that indicate exon identity during splicing. Mutated ESEs could therefore result in exon skipping during splicing. Eight of 24 non-truncating exonic base changes (33\%) in the African population fall within high scoring predicted ESE, and the base substitutions associated with five of these alleles are predicted to cause ESE disruption (BRCA2 A248T, Q713L, T1414M, D1902N, and V2171V). Two of these (T1414M and $\mathrm{V} 217 \mathrm{lV})$ are seen in our unaffected population as well as in patients. It is important to note that ESE mediated splicing patterns are complex, and not all disruptions of predicted ESE consensus motifs will necessarily result in high penetrance exon skipping phenotypes. However, such a mutation could cause shifts in relative levels of alternate splicing products, resulting in limited or conditional clinical phenotypes. Finally, we used methods on the SIFT website to predict which amino acid substitutions found in BRCAl and BRCA2 protein variants in the African population are unlikely to be tolerated at mutant positions (see Methods). Of these variants, all the amino acid substitutions seen in BRCAl (I379M, K820E, and K1183R) are predicted to contain nontolerated amino acid substitutions by scoring based on homolog alignment, and are thus potentially clinically important base changes. Interestingly, BRCAl I379M was also identified as a potentially deleterious amino acid substitution by an "ancestral sequence" method..$^{33}$ Of the BRCA2 amino acid substitutions seen in the African cohort, alleles N987I, N991D, and I2944F are predicted to be nontolerated amino acid substitutions within the limits of confidence in the alignments.

Neither ESE nor SIFT scoring mechanisms constitute definitive evidence of the clinically deleterious nature of the base changes observed. However, they suggest a rational and testable basis for anticipating that many of the functionally uncharacterised mutations described here could be deleterious alleles, perhaps some with limited penetrance. Unfortunately, we do not have additional biological materials to carry out further tests on the patients. Nonetheless, we suggest that the numerous variations in BRCAl and especially $B R C A 2$ in African breast cancer patients may contribute to disease occurrence and should be characterised functionally.

\section{DISCUSSION}

We previously investigated the frequency of $B R C A 1$ and $B R C A 2$ protein truncating mutations in a cohort of 70 young breast cancer patients ascertained in the surgical oncology unit at the University College Hospital Ibadan, Nigeria. ${ }^{22}$ We reported $4 \%$ of the population carried deleterious mutations (two truncating mutations in BRCAl and one in BRCA2), well below the frequencies of deleterious mutations found in other clinic or population based cohorts. ${ }^{34}$ However, we also reported a preliminary observation of 20 non-truncating $B R C A 2$ variants in 18 individuals (23\%). In the present study we re-examined a subset of the original population to better define the frequency of BRCA1 and BRCA2 non-truncating alleles and assess whether these may also be a source of breast cancer susceptibility in young African breast cancer patients. Here we report a single truncating BRCA2 mutation and no additional truncating mutations in the 39 patient cohort $(2.6 \%)$, but $29(74 \%)$ carried non-truncating variants in BRCA2. These observations are expand our previous observations and are consistent with observations by Wagner and colleagues, who found 45 different BRCA2 sequence variants in 21 unrelated unaffected African individuals, with 33 of 45 (73.3\%) being unique to African populations (reported in BIC or for the first time in 1998). ${ }^{29}$ Other studies using different mutation ascertainment methods have shown high levels of $B R C A 2$ sequence variability and a distinct spectrum of variants in patients of African ancestry. ${ }^{29} 35$ This observation is consistent with reports of an exceptionally high level of overall genetic diversity in people of African ancestry. ${ }^{29} 36$

Newman and colleagues reported a lower frequency of deleterious BRCAl mutations in black than in white women $(3.3 \% v 0 \%)$ in a population of unrelated patients diagnosed 
Table $2 B R C A 1$ and $B R C A 2$ alleles detected in a Nigerian cohort

\begin{tabular}{|c|c|c|c|c|c|c|c|c|}
\hline Patient & BRCA gene & Base change & Exon & $\begin{array}{l}\text { Predicted amino } \\
\text { acid effect }\end{array}$ & $\begin{array}{l}\text { No of times } \\
\text { in } 39 \mathrm{pts}\end{array}$ & $\begin{array}{l}\text { No in } 74 \\
\text { unaffected } \\
\text { individuals }\end{array}$ & $\begin{array}{l}\text { BIC designation } \\
\text { (occurrences in } \mathrm{BIC} \text { ) }\end{array}$ & Global heterozygosity \\
\hline \multicolumn{9}{|c|}{ Single nucleotide substitutions } \\
\hline 1 & BRCAl & $1256 \mathrm{~T} \rightarrow \mathrm{G}$ & 11 & I379M & 1 & ND & UV (15) & \\
\hline 2 & BRCA1 & $2577 A \rightarrow G$ & 11 & K820E & 1 & ND & UV (28) & \\
\hline 3 & BRCAl & $2933 A \rightarrow G$ & 11 & P938P & 1 & ND & $P(2)$ & \\
\hline 4 & BRCA1 & $3667 \mathrm{~A} \rightarrow \mathrm{G}$ & 11 & K1183R & 1 & ND & $P(32)$ & 0.403 \\
\hline 5 & BRCA2 & $970 \mathrm{G} \rightarrow \mathrm{A}$ & 9 & $\mathrm{~A} 248 \mathrm{~T}$ & 1 & 0 & UV (1) & \\
\hline 6 & BRCA2 & $1093 \mathrm{~A} \rightarrow \mathrm{C}$ & 10 & $\mathrm{~N} 289 \mathrm{H}$ & 1 & ND & UV (2) & 0.120 \\
\hline 7 & BRCA2 & $1503 A \rightarrow G$ & 10 & E425E & 2 & ND & lst report (0) & \\
\hline 8 & BRCA2 & $\mathrm{A} 2366 \mathrm{~T}$ & 11 & Q713L & 2 & 0 & $U V^{*}(8)$ & \\
\hline 9 & BRCA2 & $3014 \mathrm{~T} \rightarrow \mathrm{C}$ & 11 & L929S & $\overline{1}$ & 5 & UV (29) & \\
\hline 10 & BRCA2 & $3188 \mathrm{~A} \rightarrow \mathrm{T}$ & 11 & N987I & 1 & 2 & UV (29) & \\
\hline 11 & BRCA2 & $3199 \mathrm{~A} \rightarrow \mathrm{G}$ & 11 & N991D & 4 & 3 & UV (1) & 0.15 \\
\hline 12 & BRCA2 & $3492 \mathrm{~T} \rightarrow \mathrm{C}$ & 11 & P1088P & 2 & ND & $P(6)$ & \\
\hline 13 & BRCA2 & $4299 A \rightarrow C$ & 11 & L1357L & 1 & ND & 1st report (0) & \\
\hline 14 & BRCA2 & $4469 \mathrm{C} \rightarrow \mathrm{T}$ & 11 & $\mathrm{~T} 1414 \mathrm{M}$ & 1 & 1 & UV (26) & 0.012 \\
\hline 15 & BRCA2 & $4791 \mathrm{G} \rightarrow \mathrm{A}$ & 11 & L1521L & 1 & ND & $\mathrm{P}^{*}(2)$ & 0.018 \\
\hline 16 & BRCA2 & $5646 \mathrm{~A} \rightarrow \mathrm{G}$ & 11 & E1806E & 2 & ND & lst report (0) & \\
\hline 17 & BRCA2 & $5932 \mathrm{G} \rightarrow \mathrm{A}$ & 11 & D1902N & 1 & 0 & UV (59) & 0.012 \\
\hline 18 & BRCA2 & $5938 \mathrm{C} \rightarrow \mathrm{G}$ & 11 & L1904V & 2 & 0 & UV (8) & \\
\hline 19 & BRCA2 & $6741 \mathrm{C} \rightarrow \mathrm{G}$ & 11 & V2171V & 4 & 16 & $P(1)$ & 0.018 \\
\hline 20 & BRCA2 & $7378 C \rightarrow A$ & 14 & Q2384K & 1 & 0 & UV (18) & \\
\hline 21 & BRCA2 & $7470 A \rightarrow G$ & 14 & S2414S & 1 & ND & $P(10)$ & 0.250 \\
\hline 22 & BRCA2 & $7547 \mathrm{~A} \rightarrow \mathrm{G}$ & 14 & $\mathrm{H} 2440 \mathrm{R}$ & 2 & 2 & UV (79) & \\
\hline 23 & BRCA2 & $9058 \mathrm{~A} \rightarrow \mathrm{T}$ & 22 & $12944 \mathrm{~F}$ & 3 & 1 & UV (115) & 0.006 \\
\hline 24 & BRCA2 & $9862 \mathrm{G} \rightarrow \mathrm{C}$ & 26 & G3212R & 2 & 2 & $U V^{*}(8)$ & \\
\hline 25 & BRCA2 & $3034 / 6$ delACAA & 11 & $958 x$ & 1 & ND & trunc (63) & \\
\hline \multicolumn{9}{|c|}{ Intronic variations } \\
\hline 26 & BRCA2 & ex2-11C $\rightarrow T$ & & - & 4 & ND & 1st report (0) & \\
\hline 27 & BRCA2 & ex7-19C $\rightarrow T$ & & - & 2 & ND & UV (10) & \\
\hline 28 & BRCA2 & ex $11-43 T \rightarrow C$ & & - & 2 & ND & lst report (0) & \\
\hline 29 & BRCA2 & ex 12-200insC & & - & $\overline{1}$ & ND & lst report (0) & \\
\hline 30 & BRCA2 & ex $17-40 A \rightarrow G$ & & - & 3 & ND & lst report (0) & \\
\hline 31 & BRCA2 & ex $18+109 G \rightarrow A$ & & - & 2 & 0 & lst report (0) & \\
\hline 32 & BRCA2 & ex21-36C $\rightarrow G$ & & - & $\overline{1}$ & ND & lst report (0) & \\
\hline 33 & BRCA2 & ex $22-70 C \rightarrow T$ & & - & 2 & ND & lst report (0) & \\
\hline 34 & BRCA2 & ex26+106delT & & - & 2 & ND & $P(1)$ & \\
\hline \multicolumn{9}{|c|}{$\begin{array}{l}\text { Alleles reported here for the first time or found only in Africans or African Americans are in bold. Global heterozygosity frequency was known only in some cases. } \\
\text { The heterozygosity frequency of } B R C A 1 \mathrm{~K} 1183 R \text { was taken from the NCBI SNP page }<\mathrm{http} / / / \mathrm{www} \text {. ncbi.nlm. nih. gov } / \mathrm{SNP} />\text {, and the rest were taken from } \\
\text { Wagner et al. } \text {. }^{29} \text { The asterisk indicates alleles reported in patients of African ancestry and at least one patient of unreported ethnicity. Such alleles could be specific } \\
\text { to populations of African ancestry, but this cannot be determined by the information available in BIC. For example, the } B R C A 2 \mathrm{~L} 1521 \mathrm{~L} \text { variant was shown to be } \\
\text { specific to African individuals in the study by Wagner et al. }{ }^{29} \\
\mathrm{ND} \text {, not determined; (P), polymorphism; pts, patients; trunc, truncating; UV, unclassified variant. }\end{array}$} \\
\hline
\end{tabular}

with invasive breast cancer, but not selected for early age onset or family history. ${ }^{37}$ Other studies indicate that frequencies of deleterious BRCA1 and BRCA2 mutations are just as common in African American high risk patients as in other ethnic groups. ${ }^{11}{ }^{38-40}$ However, these studies used clinic based subjects who were referred for genetic testing based on family history, whereas our consecutively ascertained clinic based subjects were selected only for early onset breast cancer. Indeed, it has been shown that rigorous family history criteria predict deleterious BRCAI and BRCA2 mutations just as strongly in African Americans as other populations. ${ }^{11} 353840$ However, these findings are unlikely to reflect the distribution of BRCAI and BRCA2 mutations in general populations, which may explain the similarity between our results and those of Newman et al. ${ }^{37}$

Other studies of genetic contributions to breast cancer in different ethnic groups have revealed population specific patterns of BRCAI and BRCA2 mutation frequencies and spectra associated with breast cancer. Patient selection criteria and mutation detection methods vary widely in these studies, so it is difficult to compare mutation frequencies among published investigations. However, several reveal that both the frequency of variants and deleterious mutations is higher in BRCA2 than BRCA1. This has been seen in populations from Mexico, ${ }^{41}$ Spain ${ }^{42}$ Sardinia, ${ }^{43}$ and Japan. ${ }^{44}$ One study that examined a population of Indian breast cancer patients showed similar frequencies of variants per se in BRCA1 and BRCA2, but all the BRCAI variants were deleterious, while all the $B R C A 2$ variants were clinically unclassified. ${ }^{45}$ Finally, several studies have described populations in which the frequency of unclassified variants and deleterious mutations in BRCAl are both more frequent than in BRCA2. These include cohorts from the USA, ${ }^{46}{ }^{47}$ Canada, $^{48}$ Germany, ${ }^{49} 50$ and China. ${ }^{51}$ The observation that our African cohort showed a much greater frequency of variability in $B R C A 2$ than BRCA1 is surprising, as breast cancers in BRCAl mutation carriers have more clinical similarity to breast cancers in patients of African descent. It remains possible that some of the patients carry distant promoter mutations, splice disrupting mutations deep within intronic regions, or large scale rearrangements of BRCAl not detected by our methods. Additionally, it is possible that BRCAl mutation carriers simply have breast cancer characteristics in common with other early onset breast cancers, and such characteristics will probably occur with a high frequency in disproportionately young populations. Germline BRCA2 mutations are associated with early onset breast cancers that are otherwise phenotypically similar to sporadic breast cancers. ${ }^{52}$ Because of the frequency of the unclassified variants in our Nigerian population, we suggest that some of these variants may be deleterious to some extent. It is interesting to note that, in a clinic based cohort of African Americans with family histories 
of breast cancer, who are thus more likely to carry BRCAl/2 mutations, the frequency of BRCA2 single base changes is even higher than in the age selected Nigerian cohort (Fackenthal JD and Olopade OI, unpublished observations).

Among the most clinically useful observations from BRCAI and $B R C A 2$ genetic analyses in individual ethnic populations is the existence of population specific founder mutations. For example, among Ashkenazi Jews, $20 \%$ of patients diagnosed before the age of 40 carry the BRCAl 185delAG allele, whereas only $10 \%$ of a general white population with early onset breast cancer may carry BRCAl mutations of any kind. ${ }^{53}$ Additionally, the BRCA2 999del5 allele has been identified as a founder mutation in the Icelandic population and has been detected in $0.6 \%$ of the total population, $7.7 \%$ of all female breast cancers, and $40 \%$ of all male breast cancers. ${ }^{55-57}$ In populations of African descent, such founder mutations have been difficult to identify, possibly because of the diversity in the African diaspora. Several reports have shown that a single allele, BRCA1 943ins10, is common to patients of African ancestry detected in Washington DC, Florida, South Carolina, Bahamas, and the Ivory Coast. ${ }^{58-61}$ This allele does not occur often enough to provide expediency in clinical diagnostics, but it does suggest that the mutational spectrum of BRCAl/2 may be distinctive in Africans and African Americans.

The mutations identified in BRCA2 in our Nigerian cohort were distributed throughout the coding region and did not fall predominantly into known functional domains or cluster into potential novel domains. Several amino acid substitutions occurred more than once, and some of these have been reported only in African or African American individuals, or are reported here for the first time (table 2). While these variants may contribute to a unique spectrum of BRCA2 mutations in subSaharan African populations, we cannot conclude from currently available data that these alleles are unique to individuals of African ancestry.

However, the unique spectrum of BRCA2 alleles seen in these African patients may reflect $B R C A 2$ involvement in early onset breast cancer in African populations. Several observations suggest that some of these mutations may represent deleterious or incompletely penetrant alleles. First, five of 13 amino acid substitutions (38\%) that were detected in the breast cancer population were not detected in the control population. While our sample size is too small for definitive statistical analysis, this observation suggests these alleles could be rare high risk alleles. Additionally, eight of 14 BRCA2 exonic single base substitutions (57\%) fell within high scoring ESE motifs, and the majority of these are motif disrupting alleles that could result in exon skipping. ESE disruption alleles that result in exon skipping have been reported in numerous cancer related genes, including $B R C A I$ and BRCA2.25316263 Finally, all three BRCAl amino acid substitutions and three of 13 BRCA2 amino acid substitutions $(23 \%)$ are predicted to be disruptive to protein structure based on scoring from alignment of homologs. Many DNA sequence variants that result in an alteration of protein structure, protein binding ability, or aberrant splicing patterns are likely to have limited penetrance or be dependent upon genetic or environmental backgrounds for expressivity. To address the potentially subtle nature of such hypothetical alleles, it will be necessary to construct haplotypes containing variants of interest in linkage disequilibrium with other markers. Such haplotypes are potentially more likely to cosegregate with disease than any single marker component. Taken together, these observations suggest that the high variability of BRCAl and BRCA2 sequences could contribute to early onset breast cancers seen in patients of African descent. We suggest that functional characterisation of non-truncating alleles like the ones reported here will be necessary in the future in order to understand the structural requirements for $B R C A 1 / 2$ tumour suppressor functions and provide informed genetic counselling for patients from ethnically diverse backgrounds.

\section{ACKNOWLEDGEMENTS}

This work was supported by grants from the Falk Medical Research Trust, US Army Department of Defense, and NCl-CA 89085 (support to OIO). OIO is a Doris Duke Distinguished Clinical Scientist.

\section{Authors' affiliations}

J D Fackenthal, L Sveen, E K Kohlmeir*, O I Olopade, Department of Medicine, University of Chicago, Chicago, Illinois, USA

Q Gao, Department of Medical and Molecular Genetics, Indiana University School of Medicine, Indianapolis, Indiana, USA

C Adebamowo, T O Ogundiran, A A Adenipekun, R Oyesegun, O Campbell, E E U Akang, College of Medicine, University of Ibadan, Ibadan, Nigeria

C Rotimi, Department of Microbiology, National Human Genome Center at Howard University College of Medicine, Washington DC, USA

S Das, Department of Human Genetics, University of Chicago

*Dr E K Kohlmeir's current affiliation: Northwestern University, Evanston, Illinois, USA

Competing interests: none declared

Correspondence to: $\operatorname{Dr} O \mathrm{I}$ Olopade, Department of Medicine, MC21 15, University of Chicago, 5841 S Maryland Ave, Chicago, IL 60637, USA; folopade@medicine.bsd.uchicago.edu

\section{REFERENCES}

1 Couch FJ, DeShano ML, Blackwood MA, Calzone K, Stopfer J, Campeau L, Ganguly A, Rebbeck T, Weber BL. BRCA1 mutations in women attending clinics that evaluate the risk of breast cancer. $N$ Engl J Med 1997:336:1409-15.

2 Frank TS, Manley SA, Olopade OI, Cummings S, Garber JE, Bernhardt B, Antman K, Russo D, Wood ME, Mullineau L, Isaacs C, Peshkin B, Buys S, Venne V, Rowley PT, Loader S, Offit K, Robson M, Hampel H, Brener D, Winer EP, Clark S, Weber B, Strong LC, Thomas A. Sequence analysis of $B R C A 1$ and $B R C A 2$ : correlation of mutations with family history and ovarian cancer risk. J Clin Oncol 1998;16:2417-25.

3 Ganguly A, Leahy K, Marshall AM, Dhulipala R, Godmilow L, Ganguly T. Genetic testing for breast cancer susceptibility: frequency of BRCA1 and BRCA2 mutations. Genetic Testing 1997;1:85-90.

4 Ford D, Easton DF, Stratton M, Narod S, Goldgar D, Devilee P, Bishop DT, Weber B, Lenoir G, Chang-Claude J, Sobol H, Teare MD, Struewing J, Arason A, Scherneck S, Peto J, Rebbeck TR, Tonin P, Neuhausen S, Barkardottir R, Eyfiord J, Lynch H, Ponder BA, Gayther SA, ZeladaHedman M. Genetic heterogeneity and penetrance analysis of the BRCAl and BRCA2 genes in breast cancer families. The Breast Cancer Linkage Consortium. Am J Hum Genet 1998;62:676-89

5 Montagna M, Santacatterina M, Torri A, Menin C, Zullato D, Chieco-Bianchi L, $D^{\prime}$ Andrea $\mathrm{E}$. Identification of a $3 \mathrm{~kb}$ Alu-mediated BRCAl gene rearrangement in two breast/ovarian cancer families. Oncogene 1999; 18:4160-5.

6 Petrij-Bosch A, Peelen T, van Vliet M, van Eijk R, Olmer R, Drusedau M, Hogervorst FB, Hageman S, Arts PJ, Ligtenberg MJ, Meijers-Heiiboer $H_{\text {, }}$ Klijn JG, Vasen HF, Cornelisse CJ, van't Veer U, Bakker E, van Ommen GJ, Devilee P. BRCA1 genomic deletions are major founder mutations in Dutch breast cancer patients. [Erratum appears in Nat Genet 1997;17:503.] Nat Genet 1997:17:341-5.

7 Puget N, Torchard D, Serova-Sinilnikova OM, Lynch HT, Feunteun J, Lenoir GM, Mazoyer S. A 1-kb Alu-mediated germ-line deletion removing BRCA1 exon 17. Cancer Res 1997; 57:828-31.

8 Puget N, Stoppa-Lyonnet D, Sinilnikova OM, Pages S, Lynch HT, Lenoir GM, Mazoyer S. Screening for germ-line rearrangements and regulatory mutations in BRCAl led to the identification of four new deletions. Cancer Res 1999;59:455-61.

9 Swensen J, Hoffman M, Skolnick MH, Neuhausen SL. Identification of a 14 kb deletion involving the promoter region of BRCA1 in a breast cancer family. Hum Mol Genet 1997;6:1513-17.

10 Unger MA, Nathanson KL, Calzone K, Antin-Ozerkis D, Shih HA, Martin AM, Lenoir GM, Mazoyer S, Weber BL. Screening for genomic rearrangements in families with breast and ovarian cancer identifies BRCAl mutations previously missed by conformation-sensitive gel electrophoresis or sequencing. Am J Hum Genet 2000;67:841-50

11 Olopade OI, Fackenthal JD, Dunston G, Tainsky MA, Collins F, WhitfieldBroome C. Breast cancer genetics in African Americans. Cancer 2003;97(suppl):236-45

12 Hankey BF, Miller B, Curtis R, Kosary C. Trends in breast cancer in younger women in contrast to older women. J Natl Cancer Inst Monogr 1994:7-14. 
13 Adebamowo CA, Adekunle OO. Case-controlled study of the epidemiological risk factors for breast cancer in Nigeria. Br J Surg 1999;86:665-8.

14 Ihekwaba FN. Breast cancer in Nigerian women [see comments]. Br J Surg 1992;79:771-5.

15 Phillips KA, Nichol K, Ozcelik H, Knight J, Done SJ, Goodwin PJ, Andrulis IL. Frequency of p53 mutations in breast carcinomas from Ashkenazi Jewish carriers of BRCA1 mutations. J Natl Cancer Inst 1999;91:469-73.

16 Marcus JN, Watson P, Page DL, Narod SA, Lenoir GM, Tonin P, LinderStephenson L, Salerno G, Conway TA, Lynch HT. Hereditary breast cancer: pathobiology, prognosis, and BRCA1 and BRCA2 gene linkage. Cancer 1996;77:697-709.

17 Verhoog LC, Brekelmans CT, Seynaeve C, van den Bosch LM, Dahmen G, van Geel AN, Tilanus-Linthorst MM, Bartels CC, Wagner A, van den Ouweland A Devilee P, Meijers-Heijboer EJ, Klijn JG. Survival and tumour characteristics of breast-cancer patients with germline mutations of BRCA1. Lancet 1998;351:316-21.

18 Marcus J, Watson P, Page DL, Narod SA, Tonin P, Lenoir GM, Serova O, Lynch $\mathrm{HT}$. BRCA1 and BRCA2 hereditary breast carcinoma phenotypes. Cancer (suppl 3) 1997:80:543-56.

19 Chen VW, Correa P, Kurman RJ, Wu XC, Eley JW, Austin D, Muss H, Hunter CP, Redmond C, Sobhan M. Histological characteristics of breast carcinoma in blacks and whites. Cancer Epidemiol Biomarkers Prev 1994;3:127-35.

20 Joslyn SA, West MM. Racial differences in breast carcinoma survival. Cancer 2000;88:114-23.

21 lkpatt OF, Kuopio T, Ndoma-Egba R, Collan Y. Breast cancer in Nigeria and Finland: epidemiological, clinical and histological comparison. Anticancer Res 2002;22:3005-12.

22 Gao $Q$ Adebamowo CA, Fackenthal J, Das S, Sveen L, Falusi AG Olopade OI. Protein truncating BRCA1 and BRCA2 mutations in African women with pre-menopausal breast cancer. Hum Genet 2000;107:192-4.

23 Gao Q, Neuhausen S, Cummings S, Luce M, Olopade OI. Recurrent germ-line BRCA1 mutations in extended African American families with early-onset breast cancer. Am J Hum Genet 1997;60:1233-6.

24 Plummer SJ, Anton-Culver H, Webster L, Noble B, Liao S, Kennedy A, Belinson J, Casey G. Detection of BRCA1 mutations by the protein truncation test. Hum Mol Genet 1995;4:1989-91.

25 Cartegni L, Chew S, Krainer A. Listening to silence and understanding nonsense: exonic mutations that affect splicing. Nat Rev 2002;3:285-300.

26 Liu HX, Zhang M, Krainer AR. Identification of functional exonic splicing enhancer motifs recognized by individual SR proteins. Genes Dev 1998:12:1998-2012.

27 Liu HX, Chew SL, Cartegni L, Zhang MQ, Krainer AR. Exonic splicing enhancer motif recognized by human SC 35 under splicing conditions. Mol Cell Biol 2000;20:1063-71.

28 BIC. BCIC: an open access on-line breast cancer mutation database, 1998.

29 Wagner TM, Hirtenlehner K, Shen P, Moeslinger R, Muhr D, Fleischmann E, Concin H, Doeller W, Haid A, Lang AH, Mayer P, Petru E, Ropp E, Langbaver G, Kubista E, Scheiner O, Underhill P, Mountain J, Stierer M, Zielinski C, Oefner P. Global sequence diversity of BRCA2: analysis of 71 breast cancer families and 95 control individuals of worldwide populations [published erratum appears in Hum Mol Genet 1999;8:717-9]. Hum Mol Genet 1999:8:413-23.

30 Cartegni L, Krainer AR. Disruption of an SF2/ASF-dependent exonic splicing enhancer in SMN2 causes spinal muscular atrophy in the absence of SMN1. Nat Genet 2002;30:377-84.

31 Fackenthal JD, Cartegni L, Krainer AR, Olopade OI. BRCA2 T2722R is a deleterious allele that causes exon skipping. Am J Hum Genet 2002;71:625-31

32 Krainer AR, Cartegni L. Listening to silence and understanding nonsense: exonic mutations that affect splicing. Nat Genet 2002;30:377-84.

33 Fleming MA, Potter JD, Ramirez CJ, Ostrander GK, Ostrander EA. Understanding missense mutations in the BRCAl gene: an evolutionary approach. Proc Natl Acad Sci USA 2003;100:1151-6.

34 Szabo Cl, King MC. Population genetics of BRCA1 and BRCA2 [editorial; comment]. Am J Hum Genet 1997;60:1013-20.

35 Kanaan Y, Kpenu E, Utley K, Adams-Campbell L, Dunston GM, Brody LC, Broome C. Inherited BRCA2 mutations in African Americans with breast and/ or ovarian cancer: a study of familial and early onset cases. Hum Genet 2003;113:452-60

36 Jorde LB, Bamshad M, Rogers AR. Using mitochondrial and nuclear DNA markers to reconstruct human evolution. BioEssays 1998;20:126-36.

37 Newman B, Mu H, Butler LM, Millikan RC, Moorman PG, King MC. Frequency of breast cancer attributable to $B R C A l$ in a population-based series of American women. JAMA 1998;279:915-21.

38 Frank TS, Deffenbaugh AM, Reid JE, Hulick M, Ward BE, Lingenfelter B, Gumpper KL, Scholl T, Tavtigian SV, Pruss DR, Critchfield GC. Clinical characteristics of individuals with germline mutations in BRCA1 and BRCA2 analysis of 10000 individuals. J Clin Oncol 2002;20:1480-90.

39 Gao Q Tomlinson G, Das S, Cummings S, Sveen L, Fackenthal J, Schumm P Olopade OI. Prevalence of BRCA1 and BRCA2 mutations among clinic-based African American families with breast cancer. Hum Genet 2000;107: 186-91.
40 Ruiz-Flores P, Sinilnikova OM, Badzioch M, Calderon-Garciduenas AL Chopin S, Fabrice O, Gonzalez-Guerrero JF, Szabo C, Lenoir G, Goldgar DE, Barrera-Saldana HA. BRCA1 and BRCA2 mutation analysis of early-onset and familial breast cancer cases in Mexico. Hum Mutat 2002;20:474-5.

41 de Sanjose $S$, Leone $M$, Berez V, Izquierdo A, Font R, Brunet JM, Louat T, Vilardell L, Borras J, Viladiu P, Bosch FX, Lenoir GM, Sinilnikova OM. Prevalence of BRCA1 and BRCA2 germline mutations in young breast cancer patients: a population-based study. Int J Cancer 2003;106:588-93.

42 Palmieri G, Palomba G, Cossu A, Pisano M, Dedola MF, Sarobba MG, Farris A, Olmeo N, Contu A, Pasca A, Satta MP, Persico I, Carboni AA, Cossu-Rocca P, Contini M, Mangion J, Stratton MR, Tanda F. BRCAl and BRCA2 germline mutations in Sardinian breast cancer families and their implications for genetic counseling. Ann Oncol 2002;13:1899-907.

43 Ikeda N, Miyoshi Y, Yoneda K, Shiba E, Sekihara Y, Kinoshita M, Noguchi S. Frequency of BRCA1 and BRCA2 germline mutations in Japanese breast cancer families. Int I Cancer 2001;91:83-8.

44 Saxena S, Barihoux L, Sinilnikova O, Lenoir G, Goldgar DE, Bhatanager D. BRCA1 and BRCA2 in Indian breast cancer patients. Hum Mutat 2002;20:473-4.

45 Shih HA, Couch FJ, Nathanson KL, Blackwood MA, Rebbeck TR, Armstrong KA, Calzone K, Stopfer J, Seal S, Stratton MR, Weber BL. BRCA and BRCA2 mutation frequency in women evaluated in a breast cancer risk evaluation clinic. I Clin Oncol 2002;20:994-9

46 Malone KE, Daling JR, Neal C, Suter NM, O'Brien C, Cushing-Haugen K, Jonasdottir TJ, Thompson JD, Ostrander EA. Frequency of BRCA1/BRCA2 mutations in a population-based sample of young breast carcinoma cases. Cancer 2000;88:1393-402.

47 Risch HA, McLaughlin JR, Cole DE, Rosen B, Bradley L, Kwan E, Jack E, Vesprini DJ, Kuperstein G, Abrahamson JL, Fan I, Wong B, Narod SA. Prevalence and penetrance of germline BRCA1 and BRCA2 mutations in a population series of 649 women with ovarian cancer. Am J Hum Genet $2001 ; 68: 700-10$

48 Hamann U, Liu X, Bungardt N, Ulmer HU, Bastert G, Sinn HP. Similar contributions of BRCA1 and BRCA2 germline mutations to early-onset breast cancer in Germany. Eur J Hum Genet 2003;11:464-7.

49 Meyer P, Voigtlaender T, Bartram CR, Klaes R. Twenty-three novel BRCAl and BRCA2 sequence alterations in breast and/or ovarian cancer families in Southern Germany. Hum Mutat 2003:22:259.

50 Zhi X, Szabo C, Chopin S, Suter N, Wang QS, Ostrander EA, Sinilnikova OM, Lenoir GM, Goldgar D, Shi YR. BRCA1 and BRCA2 sequence variants in Chinese breast cancer families. Hum Mutat 2002;20:474.

51 Breast Cancer Linkage Consortium. Pathology of familial breast cancer: differences between breast cancers in carriers of BRCA1 or BRCA2 mutations and sporadic cases [see comments]. Lancet 1997;349:1505-10.

52 Offit K, Gilewski T, McGuire P, Schluger A, Hampel H, Brown K, Swensen J, Neuhausen S, Skolnick M, Norton L, Goldgar D. Germline BRCA1 185delAG mutations in Jewish women with breast cancer. Lancet 1996;347:1643-5

53 Langston AA, Malone KE, Thompson JD, Daling JR, Ostrander EA. BRCA1 mutations in a population-based sample of young women with breast cancer [see comments]. N Engl J Med 1996;334:137-42.

54 Johannesdottir G, Gudmundsson J, Bergthorsson JT, Arason A, Agnarsson BA, Eiriksdottir G, Johannsson OT, Borg A, Ingvarsson S, Easton DF, Egilsson V, Barkardottir RB. High prevalence of the 999del5 mutation in Icelandic breast and ovarian cancer patients. Cancer Res 1996;56:3663-5.

55 Thorlacius S, Olafsdottir G, Tryggvadottir L, Neuhausen S, Jonasson JG, Tavtigian SV, Tulinius H, Ogmundsdottir HM, Eyfiord JE. A single BRCA2 mutation in male and female breast cancer families from Iceland with varied cancer phenotypes. Nat Genet 1996;13:117-19.

56 Thorlacius S, Sigurdsson S, Bjarnadottir H, Olafsdottir G, Jonasson JG, Tryggvadottir L, Tulinius H, Eyfjord JE. Study of a single BRCA2 mutation with high carrier frequency in a small population. Am J Hum Genet 1997;60:1079-84

57 Stoppa-Lyonnet D, Laurent-Puig P, Essioux L, Pages S, Ithier G, Ligot L, Fourquet A, Salmon RJ, Clough KB, Pouillart P, Bonaiti-Pellie C, Thomas G. BRCA1 sequence variations in 160 individuals referred to a breast/ovarian family cancer clinic. Institut Curie Breast Cancer Group [see comments] Am J Hum Genet 1997;60:1021-30.

58 Mefford HC, Baumbach L, Panguluri RC, Whitfield-Broome C, Szabo C, Smith S, King MC, Dunston G, Stoppa-Lyonnet D, Arena F. Evidence for a BRCAl founder mutation in families of West African ancestry. Am J Hum Genet 1999;65:575-8.

59 Panguluri RC, Brody LC, Modali R, Utley K, Adams-Campbell L, Day AA, Whiffield-Broome C, Dunston GM. BRCAl mutations in African Americans. Hum Genet 1999;105:28-31.

60 Liu HX, Cartegni L, Zhang MQ, Krainer AR. A mechanism for exon skipping caused by nonsense or missense mutations in BRCAl and other genes [see comments]. Nat Genet 2001;27:55-8.

61 Valentine CR. The association of nonsense codons with exon skipping. Mutat Res 1998;411:87-117. 